\title{
Switching From Pre-mixed Insulin to Regimens with Insulin Glargine in Type 2 Diabetes: A Prospective, Observational Study of Data From Adriatic Countries
}

\author{
Goran Petrovski (D) - Dashamir Gjergji · Aleksandra Grbic • \\ Blazenko Vukovic · Mitja Krajnc · Natasa Grulovic
}

Received: May 10, 2018 / Published online: July 3, 2018

(C) The Author(s) 2018

\section{ABSTRACT}

Introduction: Long-acting insulin analogs such as insulin glargine may offer improved glycemic control in patients with type 2 diabetes (T2D) compared to conventional insulin therapies. The objective of this study was to determine whether switching to insulin glargine had beneficial effects on glycemic control, weight gain, and incidence of hypoglycemia in patients with suboptimally managed T2D.

Enhanced Digital Features To view enhanced digital features for this article go to https://doi.org/10.6084/ m9.figshare.6608564

Electronic supplementary material The online version of this article (https://doi.org/10.1007/s13300018-0467-4) contains supplementary material, which is available to authorized users.

\section{G. Petrovski $(\square)$}

Diabetes and Metabolic Disorders, University Clinic of Endocrinology, Vodnjanska 17, 1000 Skopje, Macedonia

e-mail: goran.endo@gmail.com

D. Gjergji

Polyclinic of Specialities Nr 3, Tirana, Albania

\section{A. Grbic}

Department of Center for Diabetes with

Endocrinology, University Clinical Center of the Republic of Srpska, Banja Luka, The Republic of Srpska, Bosnia and Herzegovina
Methods: This prospective observational study was performed on 1041 patients who were suboptimally controlled on pre-mixed insulin therapy and were switched to an insulin glargine regimen. Clinical markers of glycemic control including glycosylated hemoglobin $(\mathrm{HbA} 1 \mathrm{c})<7 \% \quad(<53 \mathrm{mmol} / \mathrm{mol})$ and fasting blood glucose (FBG) levels ranging from 3.9 to $7.2 \mathrm{mmol} / \mathrm{L}$ were used for the primary outcome measures. Follow-up assessment of primary outcomes, weight gain, incidence of hypoglycemia, and patient satisfaction with the therapy was performed after three and six months of treatment.

Results: Target therapeutic values of HbA1c were achieved in $9.3 \%$ and $30.2 \%$ of patients, whereas FBG target values were achieved in $25.9 \%$ and $52.3 \%$ of patients after the third and sixth month of therapy, respectively. Both the HbA1c and FBG targets were reached in $7 \%$ and

B. Vukovic

University Clinical Center of the Republic of Srpska, Banja Luka, The Republic of Srpska, Bosnia and Herzegovina

\section{Krajnc}

Maribor University Medical Centre, Maribor,

Slovenia

N. Grulovic

Sanofi-Aventis Croatia d.o.o., Zagreb, Croatia 
$25.9 \%$ of patients at the third and sixth month of therapy, respectively. Switching to insulin glargine decreased the incidence of hypoglycemia from $49.5 \%$ to $5.2 \%$ after six months of therapy; this decrease was associated with weight loss and was well perceived by the patients.

Conclusion: Insulin glargine-based regimens are beneficial and safe therapeutic alternatives for T2D patients inadequately controlled with pre-mixed insulin.

Funding: Sanofi-Aventis Croatia d.o.o., Zagreb, Croatia.

Keywords: Basal insulin analogs; Diabetes; Insulin glargine; Pre-mixed insulin

\section{INTRODUCTION}

The prevalence of type 2 diabetes (T2D) is rapidly rising worldwide, with the most significant increases occurring in developing countries [1]. Unfortunately, few patients diagnosed with T2D are properly controlled; for instance, it was estimated that only $36 \%$ of patients in Southeastern European countries achieved the glycated hemoglobin (HbA1c) therapeutic goal of $<7 \%(<53 \mathrm{mmol} / \mathrm{mol})$ [2]. Lack of adequate treatment leads to disease complications, which places a significant burden on the healthcare system and increases socioeconomic costs [3]. Therefore, detailed prospective studies are required to find optimal therapies and to explain why, despite clinical management, some patients do not respond to therapy or suffer from adverse events such as hypoglycemia or weight gain.

Well-recognized diabetic associations (such as the American Diabetes Association, the European Association for the Study of Diabetes, and the Canadian Diabetes Association) recommend the use of basal insulin administered once daily as the initiation therapy regimen [4-6]. However, in light of recently performed clinical trials and meta-analyses, there is no clear evidence for the superiority of this regimen over pre-mixed insulin regimens when it comes to lowering HbA1c [4-6]. Moreover, pre- mixed insulin is still more frequently prescribed worldwide than basal insulin analogs due to its lower cost. Both therapies have their advantages and disadvantages, and the choice of regimen should be based on the patients' individual characteristics, lifestyle factors, and patient perception, which cannot be easily factored into strict guidelines [7]. Nevertheless, irrespective of the type of introductory regimen prescribed, there is still a large group of patients who do not reach recommended therapeutic goals.

Insulin glargine, a long-acting insulin analog engineered to achieve continuous secretion after subcutaneous injection, has shown good efficacy as an introductory therapy in various clinical trials worldwide [8-11]. Three amino acid substitutions facilitate its high solubility in the acidic $\mathrm{pH}$ of the injection formulation and its moderate solubility at physiological $\mathrm{pH}$ [12]. After subcutaneous injection, insulin glargine precipitates in the form of a depot, which gradually disassociates to release the active insulin monomers into the circulation, thereby mimicking the basal insulin secretion of nondiabetic pancreatic beta cells [12]. Because of the tightly controlled basal insulin release into the circulation, the risk of developing hypoglycemia among patients treated with insulin glargine regimens is lower compared to those treated with pre-mixed insulin [13]. However, the basal regimen with once-daily administration of insulin glargine (which is more convenient than pre-mixed insulins for patients whose lifestyles require flexible dietary and activity patterns) is often insufficient to achieve a proper postprandial glucose level, and so additional prandial (bolus) injections must be prescribed.

To date, the efficacy of insulin glargine in patients with T2D who failed to achieve therapeutic goals with pre-mixed insulin has only been addressed in a few studies [14-16]. Therefore, the aim of this study was to evaluate the effects of switching from a pre-mixed insulin therapy to regimens with insulin glargine in suboptimally treated T2D patients in Adriatic countries. 


\section{METHODS}

\section{Subjects and Study Design}

A total of 92 hospital-based physicians participated as investigators in this prospective, observational, post-marketing, multicenter study that took place between April 2013 and May 2015 in the following Adriatic countries: Bosnia and Herzegovina, Macedonia, Albania, and Slovenia. Investigators were expected to enroll adult patients with T2D who were previously inadequately controlled with pre-mixed insulin and switched to the insulin glargine regimen with or without $( \pm)$ orally administered antidiabetic drugs (OADs) or \pm prandial insulin. Patients with type 1 diabetes, those who were pregnant, those with a history of secondary diabetes, or those on temporary insulin treatment were excluded from the study.

The patient observation period lasted six months from the date of inclusion (i.e., 1-3 months from the time of the first insulin glargine administration). The medical assessment and outcome measurements were performed at the time of inclusion and at three and six months from inclusion (Fig. 1). Because of the noninterventional nature of the study, the decision to use a particular type of insulin glargine therapy regimen ( \pm OADs or additional rapid insulin injections) was made by the physicians, who were also responsible for the documentation of all outcomes.
This study has been approved by the appropriate ethics committees: Ethics Committee, Ministry of Health, Republic of Macedonia; Republic of Slovenia National Medical Ethics Committee; National Committee of Medical Ethics, Albania; and the ethics committees of the institutions in which the study was conducted (e.g., ethics committees of Clinical Hospital Mostar, Clinical Hospital Zenica, General Hospital Trebinje, Health Center Tuzla) in Bosnia and Herzegovina. Informed consent was obtained prior to the conduct of any studyrelated data collection procedures. Data were collected in paper form and centrally collected at the site of the company sponsor.

\section{Outcome Measures}

The primary endpoint involved analyzing HbA1c and fasting blood glucose (FBG) levels at inclusion and subsequent follow-up visits (after three and six months) to determine the mean values and the proportion of patients who achieved $\mathrm{HbA} 1 \mathrm{c}<7 \% \quad(<53 \mathrm{mmol} / \mathrm{mol})$ and FBG in the range of 3.9-7.2 $\mathrm{mmol} / \mathrm{L}$.

The secondary endpoints involved analyzing the patients' weight gain, incidence of hypoglycemia, and satisfaction with the therapy. Weight gain was assessed by measuring body mass index (BMI) and waist circumference. Data on hypoglycemia frequency (symptomatic, confirmed, nocturnal, and severe) were collected at the baseline visit, retrospectively taking into account the three months prior to introduction of insulin glargine, and

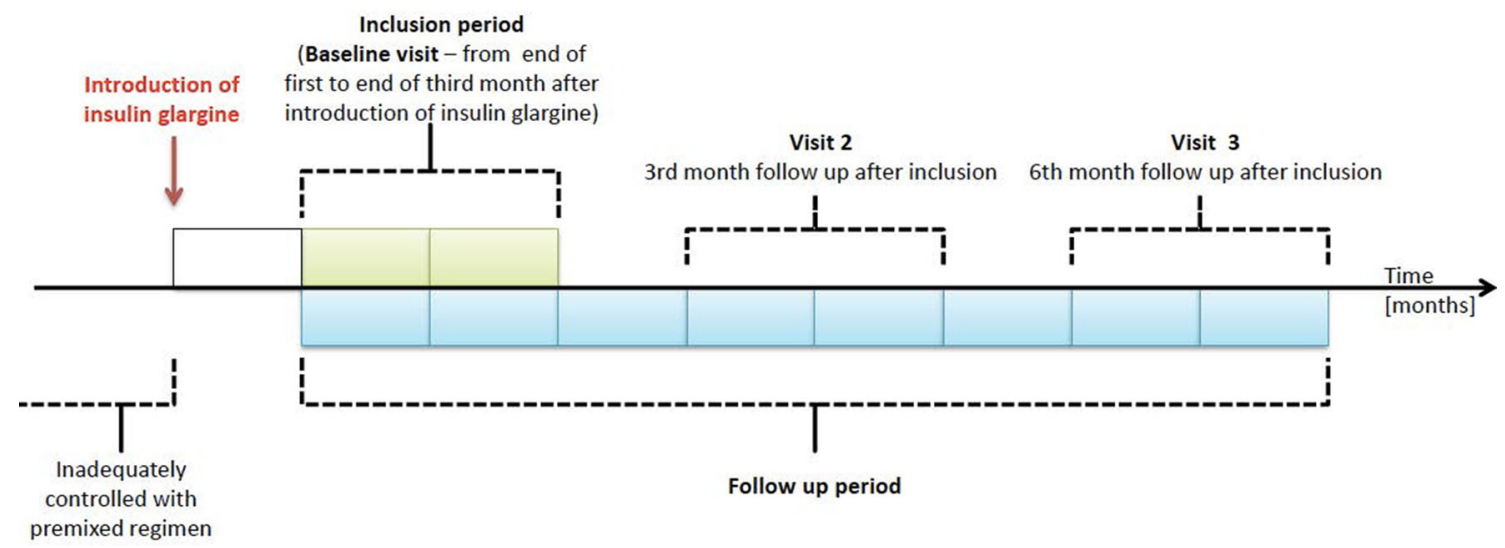

Fig. 1 Study design scheme 
prospectively at the three- and six-month follow-up visits. These data came directly from the patients, who were advised to mark every event of hypoglycemia in their diaries. Patient satisfaction with the therapy was assessed based on their answers to the question "How satisfied are you with the treatment?" Possible answers corresponded to a five-point Likert scale of either "very dissatisfied," "dissatisfied," "neither satisfied nor dissatisfied," "satisfied," or "very satisfied." All adverse events that took place from the time of signing the informed consent to the end of the study were recorded in the case report form.

\section{Statistical Analyses}

Depending on the type and number of parameters examined, the $\chi^{2}$ test, Mantel-Haenszel test, Student's $t$ test for independent or paired samples, Mann-Whitney $U$ test, Wilcoxon signed-rank test, ANOVA and posthoc analysis, and binary logistic regression were used. In all tests, a $p$ value $<0.05$ was considered statistically significant. Levene's test was used to assess equality of variances. The normal distribution of each variable was checked with the Kolmogorov-Smirnov test. For the descriptive analysis, missing data were presented as valid calculated percentages. In other analyses, missing data were excluded. All patients meeting the inclusion/exclusion criteria were included in the full data set. For the subpopulation analyses, data were divided into three sets: (1) the basal + OADs set (patients previously treated with pre-mixed insulin who were switched to insulin glargine with concomitant OADs); (2) the basal plus set (patients previously treated with pre-mixed insulin who were switched to insulin glargine with one additional daily prandial injection of rapidacting insulin); and (3) the basal bolus set (patients previously treated with pre-mixed insulin who were switched to insulin glargine with two or three additional prandial injections of rapid-acting insulin).

\section{RESULTS}

\section{Patient Characteristics at Inclusion}

A total of 1041 (606 female) patients completed the study. The mean age was $61.80 \pm 9.31$ years, with most patients ranging from 55 to 65 years of age. Mean BMI was $29.7 \pm 4.7 \mathrm{~kg} / \mathrm{m}^{2}$ and was significantly higher

Table 1 Patient characteristics at study entry

\begin{tabular}{ll}
\hline Characteristic & $\begin{array}{l}\text { All patients } \\
(n=\mathbf{1 0 4 1})\end{array}$ \\
\hline Male gender; $n(\%)$ & $435(41.8 \%)$ \\
Age; mean (SD) & $61.80 \pm 9.31$ years \\
BMI; mean (SD) & $29.7 \pm 4.7 \mathrm{~kg} / \mathrm{m}^{2}$ \\
BMI in males $(n=435) ;$ mean & $28.6 \pm 4.0 \mathrm{~kg} / \mathrm{m}^{2}$
\end{tabular}

(SD)

BMI in females $(n=606)$; mean $30.5 \pm 4.9 \mathrm{~kg} / \mathrm{m}^{2}$ (SD)

Obesity*; $n(\%)$

$446(42.9 \%)$

Overweight ${ }^{* *} ; n(\%)$

$462(44.4 \%)$

Central obesity ${ }^{* * *} ; n(\%)$

$837(80.4 \%)$

Diabetes duration; mean (SD)

$11.4 \pm 6.0$ years

Family history of diabetes; $n$ (\%)

$617(59.3 \%)$

Arterial hypertension; $n$ (\%)

$752(72.2 \%)$

Dyslipidemia; $n$ (\%)

$508(48.8 \%)$

Diabetes complications present in $>10 \%$ of patients

Diabetic neuropathy; $n$ (\%) $432(41.5 \%)$

Diabetic retinopathy; $n$ (\%)

$368(35.4 \%)$

Angina pectoris; $n$ (\%)

$140(13.4 \%)$

Macroangiopathy

$131(12.6 \%)$

Diabetic nephropathy

$115(11.0 \%)$

$B M I$ body mass index, $S D$ standard deviation

${ }^{*}$ Defined as BMI $\geq 30 \mathrm{~kg} / \mathrm{m}^{2}$

** Defined as BMI $\geq 25$ and $<30 \mathrm{~kg} / \mathrm{m}^{2}$

*** Defined according to ethnicity-specific values for waist circumference listed in the 2006 International Diabetes Federation Consensus ( $\geq 80 \mathrm{~cm}$ for females and $\geq 94 \mathrm{~cm}$ for males) [17] 
in females $\left(30.5 \pm 4.9 \mathrm{~kg} / \mathrm{m}^{2}\right)$ than in males $\left(28.6 \pm 4.0 \mathrm{~kg} / \mathrm{m}^{2} ; p<0.01\right)$. Complications and/or comorbidities were reported in 855 $(82.1 \%)$ patients; the most common complications were diabetic neuropathy $(41.5 \%$ of the studied population) and diabetic retinopathy (35.4\%). Patient characteristics at study entry are presented in Table 1.

In terms of concomitant medications, biguanides (836 patients, $80.3 \%$ ) and sulfonylureas (783 patients, $75.2 \%$ ) were the most commonly administered OADs prior to study entry. A total of 748 (71.8\%) patients continued OAD therapy at the baseline visit; however, while biguanides remained frequently used after the switch to insulin glargine (639 patients, $61.4 \%$ at baseline), sulfonylureas were mostly discontinued by the time of the baseline visit. A total of 295 patients $(28.3 \%)$ received no OADs at baseline, and the use of non-biguanide OADs was uncommon, ranging from 13 patients $(1.2 \%)$ for sulfonylureas to $54(5.4 \%)$ for sulfonylurea + biguanide combination. See the Electronic spplementary material (ESM) for more information on concomitant antidiabetic therapy at baseline and during the study period.

\section{Efficacy of the Insulin Glargine Regimen}

From the time of insulin glargine introduction, $461(44.9 \%)$ patients were treated with the basal + OADs regimen, $125(12.2 \%)$ patients with the basal plus regimen, and 441 (42.9\%) patients with the basal bolus regimen. After three months, $44.6 \%$ of patients were on the basal + OADs regimen, $12.3 \%$ of patients were on the basal plus regimen, and $43.1 \%$ of patients were on the basal bolus regimen. After six months, $44.6 \%$ of patients were treated with the basal + OADs regimen, $12.2 \%$ with the basal plus regimen, and $43.1 \%$ with the basal bolus regimen. To determine whether switching to insulin glargine is beneficial for patients inadequately treated with pre-mixed insulin, we set strict therapeutic goals to assign efficacy. Overall, the primary goal of obtaining HbA1c $<7 \%$ was reached in $9.3 \%$ and $30.2 \%$ of patients at month three and month six of therapy, respectively. Similarly, the secondary goal of achieving HbA1c levels $<7 \%$ and FBG levels in the range $3.9-7.2 \mathrm{mmol} / \mathrm{L}$ was reached in 73 patients $(7 \%)$ after three months and in $270(25.9 \%)$ patients after six months of therapy. A significantly higher percentage of patients achieved this therapeutic goal at month six of observation compared to month three $(p<0.01)$. FBG levels within the targeted plasma concentration range $(3.9-7.2 \mathrm{mmol} / \mathrm{L})$ were noted in $34(3.3 \%)$ patients at inclusion, in $298(28.6 \%)$ at the three-month follow-up visit, and in $544(52.3 \%)$ patients at the six-month follow-up visit, with the increase in prevalence being statistically significant $(p<0.01$; Fig. 2$)$. A similar statistically significant increase in the proportion of patients reaching both therapeutic goals from month three to month six of observation was observed among all three prescribed regimens (data not shown).

A significantly smaller percentage of patients reached the composite therapeutic target (i.e., $\mathrm{HbA} 1 \mathrm{c}<7.0 \%$ and FBG $3.9-7.2 \mathrm{mmol} / \mathrm{L}$ without events of hypoglycemia) after six months of therapy in the group treated with the basal bolus regimen compared to the two other regimens: 92 (21.1\%) patients reached the target in the basal bolus group versus 46 (37.4\%) in the basal plus group and 125 (28\%) in the basal + OADs group $(p<0.01)$. Despite those differences, the increase in the proportion of patients reaching the composite therapeutic target from month three to month six was similar across the three subgroups, irrespective of the prescribed regimen.

The mean value of HbA1c among the study population decreased significantly throughout the observation period-from $9.5 \pm 1.6 \%$ at baseline to $8.3 \pm 1.3 \%$ at three months, and to $7.5 \pm 1.1 \%$ at the six-month follow-up visit. Similar positive outcomes were observed for FBG: its plasma concentration decreased from $12.1 \pm 3.7 \mathrm{mmol} / \mathrm{L}$ at baseline to $8.7 \pm 2.6 \mathrm{mmol} / \mathrm{L}$ at three months, and to $7.7 \pm 2.1 \mathrm{mmol} / \mathrm{L}$ at the six-month follow-up visit.

\section{Safety of Insulin Glargine Therapy}

No severe cases of hypoglycemia were observed throughout the study in patients who switched 


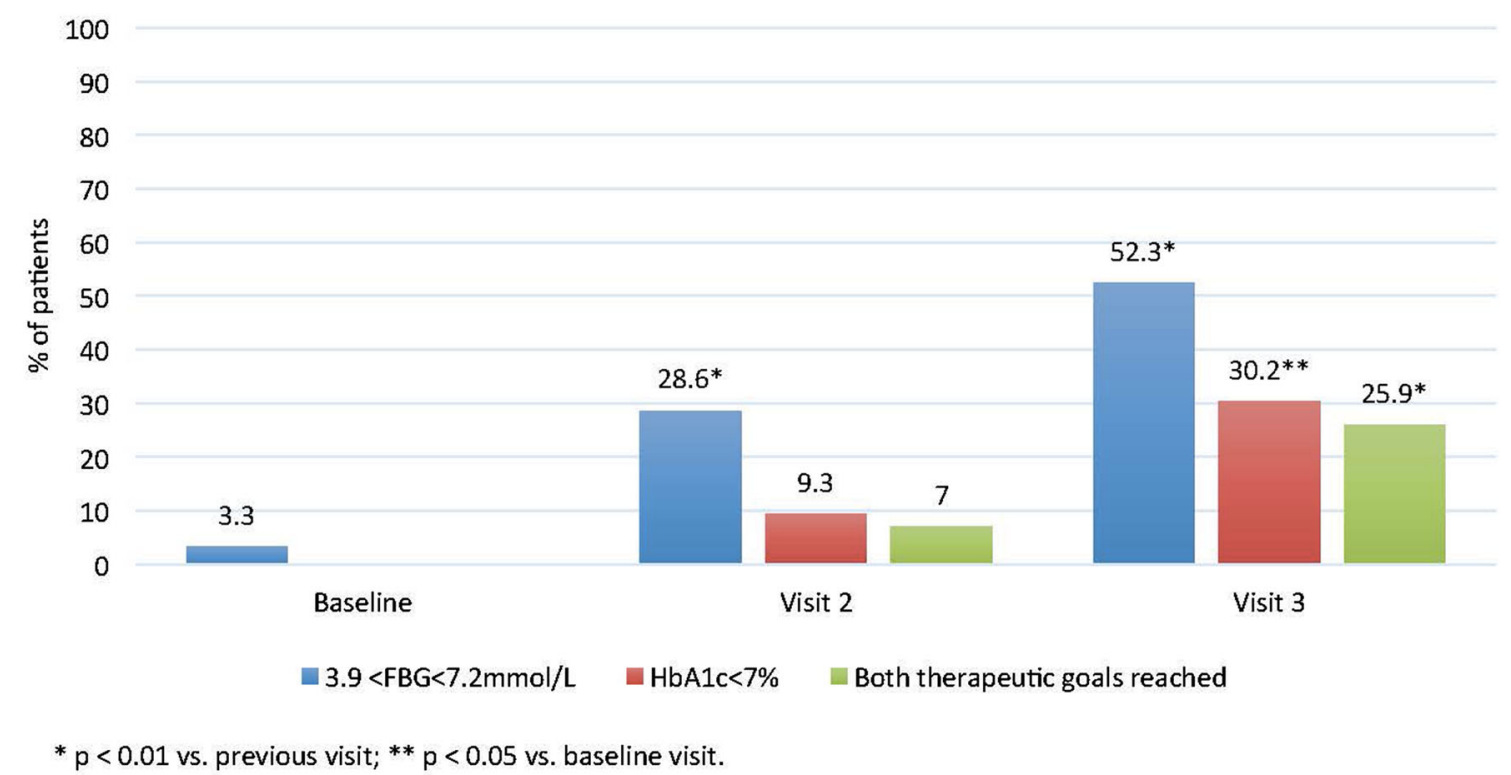

Fig. 2 Percentages of patients for whom the therapeutic goals of HbAlc, fasting blood glucose (FBG), or both HbAlc and FBG were reached

to the insulin glargine regimen. The reported serious adverse events included two cases of myocardial infarction and one case of trimalleolar fracture of the right ankle. The data on reported hypoglycemic events are shown in Table 2. Basal insulin glargine therapy was accompanied by a significant decrease in the number of hypoglycemia events reported by patients. Before switching to insulin glargine therapy, $45.9 \%$ of patients reported at least one event of hypoglycemia, whereas only $8.5 \%$ and $5.2 \%$ of patients reported these events at the three-month and six-month follow-up visit, respectively. Regarding the particular types of hypoglycemia, the most significant decrease in the number of hypoglycemic events was observed for nocturnal hypoglycemia: $2.4 \%$ vs. $0.8 \%$ between the three-month and six-month follow-up visits, respectively. The proportion of patients who experienced hypoglycemia was much higher in those receiving the basal bolus regimen compared to those receiving the basal + OADs or basal plus regimen (Table 3). This was somewhat expected, as the basal bolus regimen showed the lowest efficacy in terms of the composite endpoint.

In the full study population, body weight and waist circumference decreased significantly during the follow-up period (Table 4). Waist circumference was reduced in $566(59.1 \%)$ patients and BMI in $587(57.8 \%)$ patients over the study period. Conversely, increases in waist circumference and BMI were observed in 168 $(17.6 \%)$ and $251(24.9 \%)$ of the patients, respectively; 233 (23.3\%) patients experienced no change in waist circumference and 176 (17.3\%) experienced no change in BMI. It is worth noting that patients whose BMI decreased during the study had significantly higher starting BMI $\left(30.7 \mathrm{~kg} / \mathrm{m}^{2}\right)$ than those whose BMI remained unchanged $\left(28.7 \mathrm{~kg} / \mathrm{m}^{2}\right)$ or increased $\left(28.3 \mathrm{~kg} / \mathrm{m}^{2}\right)(p<0.05$ for both comparisons). In terms of concomitant OADs, patients whose waist circumference or BMI decreased during the study period were more likely to receive metformin and less likely to receive no OAD therapy than those whose waist circumference or BMI increased or remained unchanged (Table S3 in the ESM). We detected no association between non-metformin OAD use and waist circumference or BMI change, likely due to the small number of patients receiving OADs other than metformin.

The proportion of patients with any hypoglycemic episode was significantly higher among patients whose BMI increased than 
Table 2 Proportions of patients who experienced hypoglycemic events during follow-up

\begin{tabular}{|c|c|c|c|}
\hline & $\begin{array}{l}\text { Number of patients }(\%) \text { who } \\
\text { experienced hypoglycemic events } \\
\text { at baseline (three months prior } \\
\text { to introduction of insulin } \\
\text { glargine, } n=1041 \text { ) }\end{array}$ & $\begin{array}{l}\text { Number of patients }(\%) \text { who } \\
\text { experienced hypoglycemic } \\
\text { events at the three-month } \\
\text { follow-up visit, } n=992\end{array}$ & $\begin{array}{l}\text { Number of patients (\%) who } \\
\text { experienced hypoglycemic } \\
\text { events at the six-month follow- } \\
\text { up visit, } n=1006\end{array}$ \\
\hline $\begin{array}{l}\text { Any } \\
\text { hypoglycemic } \\
\text { event }\end{array}$ & $478(45.9 \%)$ & $88(8.5 \%)$ & $54(5.2 \%)$ \\
\hline $\begin{array}{l}\geq 1 \text { nocturnal } \\
\text { hypoglycemic } \\
\text { event }\end{array}$ & ND & $25(2.4 \%)$ & $9(0.8 \%)$ \\
\hline $\begin{aligned} \geq & 1 \\
& \text { symptomatic } \\
& \text { hypoglycemic } \\
& \text { event }\end{aligned}$ & ND & $86(8.3 \%)$ & $53(5.1 \%)$ \\
\hline $\begin{array}{l}\geq 1 \text { confirmed } \\
\text { hypoglycemic } \\
\text { event }\end{array}$ & ND & $30(2.9 \%)$ & $20(1.9 \%)$ \\
\hline $\begin{array}{l}\geq 1 \text { severe } \\
\text { hypoglycemic } \\
\text { event }\end{array}$ & ND & 0 & 0 \\
\hline
\end{tabular}

$N D$ no data

Table 3 Proportion of patients who experienced hypoglycemic episodes according to the therapy regimen

\begin{tabular}{lll}
\hline Regimen & $\begin{array}{l}\text { Number of } \\
\text { patients (\%) who } \\
\text { experienced } \\
\text { hypoglycemic } \\
\text { episodes at } \\
\text { three months }\end{array}$ & $\begin{array}{l}\text { Number of } \\
\text { patients (\%) who } \\
\text { experienced } \\
\text { hypoglycemic } \\
\text { episodes at } \\
\text { six months }\end{array}$ \\
\hline Basal + OADs & $19 / 454(4.2 \%)$ & $12 / 453(2.6 \%)$ \\
Basal plus & $5 / 125(4.0 \%)$ & $3 / 124(2.4 \%)$ \\
Basal bolus & $63 / 440(14.3 \%)^{\mathrm{a}}$ & $39 / 438(8.9 \%)^{\mathrm{b}, \mathrm{c}}$ \\
\hline
\end{tabular}

$O A D$ orally administered antidiabetic drug

${ }^{a} p<0.01$ vs. other regimens at three months

b $p<0.05$ vs. basal plus at six months

c $p<0.01$ vs. basal + OADs at six months
Table 4 Changes in body weight, waist circumference, and BMI during the study

\begin{tabular}{llll}
\hline & Baseline visit & $\begin{array}{l}\text { Three-month } \\
\text { visit }\end{array}$ & $\begin{array}{l}\text { Six-month } \\
\text { visit }\end{array}$ \\
\hline $\begin{array}{l}\text { Body } \\
\text { weight } \\
(\mathrm{kg})\end{array}$ & $83.6 \pm 13.7$ & $83.0 \pm 14.2^{* *}$ & $82.4 \pm 13.3^{* *}$ \\
$\begin{array}{l}\text { Waist } \\
(\mathrm{cm})\end{array}$ & $101.0 \pm 14.3$ & $100.4 \pm 15.1^{*}$ & $99.9 \pm 15.7^{* *}$ \\
$\begin{array}{c}\mathrm{BMI}(\mathrm{kg} / \\
\left.\mathrm{m}^{2}\right)\end{array}$ & $29.7 \pm 4.7$ & $29.5 \pm 4.8^{* *}$ & $29.3 \pm 4.7^{* *}$ \\
\hline
\end{tabular}

Data are presented as mean $\pm \mathrm{SD}$

$B M I$ body mass index, $S D$ standard deviation

Paired Student's $t$ test, ${ }^{*} p<0.05,{ }^{* *} p<0.01$ vs. previous visit 
among those whose BMI decreased during the study period $(13.0 \%$ vs $6.5 \%$ at the three-month visit, $p<0.05$ and $9.9 \%$ vs $3.4 \%$ at the sixmonth visit, $p<0.01$ ); a similar relationship was observed for waist circumference $(13.7 \%$ vs $5.8 \%$ at the three-month visit, $p<0.01$ and $10.7 \%$ vs $3.2 \%$ at the six-month visit, $p<0.01$ ). There was a weak but statistically significant positive Spearman correlation between waist circumference increase and the incidence of any hypoglycemic episode, and between BMI increase and the incidence of any hypoglycemic episode (both $p<0.01$ ).

\section{Patient Satisfaction with the Therapy}

To determine whether patients were satisfied with the switch to insulin glargine therapy, we performed a five-grade (Likert scale) survey among the treated patients at baseline and at the six-month follow-up visit. A significant increase in the percentage of patients reporting being "very satisfied" with the therapy occurred over time (i.e., $56.2 \%$ at the six-month followup visit compared to $31.8 \%$ at baseline; $p$ $<0.01)$. Moreover, the majority of the patients $(94.4 \%)$ reported a willingness to continue insulin glargine therapy.

\section{DISCUSSION}

Conventional human insulin treatment, due to its nonphysiological time-action profile, is often not efficacious at achieving tight glycemic control in patients with T2D. Moreover, irregular diet and lifestyle patterns of some patients with T2D may hamper the potential benefits of such therapy. As HbA1c is determined by both fasting and postprandial blood glucose levels, excessive postprandial glucose excursions may elevate it, even when FBG levels are within the goal range. Although a regimen with pre-mixed insulin enables both postprandial glucose and FBG to be covered, prandial control with a premixed regimen is associated with a higher risk of pre-dinner and nocturnal hypoglycemia, so it may not always be optimal for reaching glycemic targets [18].
This prospective study analyzed the clinical effects of switching from a pre-mixed insulin therapy to an insulin glargine regimen in patients with inadequately controlled T2D. The six-month follow-up observations revealed that a significant proportion of the patients with advanced diabetes reached their therapeutic goals of HbA1c $<7 \%$ and FBG between 3.9 and $7.2 \mathrm{mmol} / \mathrm{L}$. The increase in the percentage of patients reaching these set goals was similar irrespective of the type of therapy. Therefore, we hypothesize that therapeutic success did not depend on the type of regimen prescribed. Fewer patients treated with the basal bolus regimen achieved the composite endpoint of $\mathrm{HbA} 1 \mathrm{c}<7 \%$, FBG $3.9-7.2 \mathrm{mmol} / \mathrm{L}$, and no hypoglycemic events. This is likely due to the occurrence of hypoglycemic events, which may be explained by the more severe disease manifestation present in this group of patients, which required more frequent prandial insulin usage. However, despite the higher risk of hypoglycemia when glargine is used as part of a basal bolus regimen, improvements in glycemic control within the set follow-up period were significant and comparable to those observed with other regimens. Therefore, insulin glargine may be a beneficial alternative even for patients with an advanced form of diabetes requiring multiple prandial insulin injections. Similar results were obtained in a previous clinical trial performed in a large, diverse, multinational population of suboptimally treated patients with T2D, in which the 24-hour basal insulin glargine $\left(\right.$ Lantus $\left.^{\circledR}\right)$ significantly improved glycemic control with a low risk of severe hypoglycemia [19].

During a six-month follow-up period, we observed a significant decrease in mean HbA1c values (from $9.5 \pm 1.6 \%$ at baseline to $8.3 \pm 1.3 \%$ at the three-month visit and to $7.5 \pm 1.1 \%$ at the six-month visit) and in recorded FBG levels (from $12.1 \pm 3.7 \mathrm{mmol} / \mathrm{L}$ at baseline to $8.7 \pm 2.6 \mathrm{mmol} / \mathrm{L}$ at the threemonth visit and to $7.7 \pm 2.1 \mathrm{mmol} / \mathrm{L}$ at the sixmonth visit). Similar decreases were obtained in a clinical trial by Davis et al., who recorded a $9.0 \pm 1.3 \%$ to $8.0 \pm 1.2 \%$ decrease in $\mathrm{HbA} 1 \mathrm{c}$ and a $9.3 \mathrm{mmol} / \mathrm{L}$ to $5.9 \mathrm{mmol} / \mathrm{L}$ decrease in FBG 24 weeks after insulin glargine initiation in 
suboptimally controlled patients with T2D on premixed insulins [19]. In the same study, mean body weight increased modestly by $0.8 \mathrm{~kg}$ in the total study group, with no significant difference observed between the different insulin glargine subgroups analyzed. However, in our study, we observed a significant reduction in body weight, waist circumference, and BMI at each follow-up visit compared to the previous visit, with an average reduction in body weight of $1.2 \mathrm{~kg}$ between the baseline visit and the six-month follow-up visit. Importantly, reductions in body weight and BMI were experienced by nearly $60 \%$ of the patients each. A more detailed investigation revealed that concomitant $\mathrm{OAD}$ therapy may have played a role in these findings, since patients experiencing a decrease in BMI or waist circumference during the study period were more likely to use metformin and less likely to receive no OAD treatment compared with those whose BMI or waist circumference increased. Thus, the positive effects of concomitant metformin therapy in patients treated with insulin glargine in our study were consistent with metformin being widely recognized as promoting weight loss [20].

We found that an increase in BMI or waist circumference during the study directly correlated with the number of any hypoglycemic episode. As patients with an increase in BMI over the study period had a significantly lower baseline BMI compared with those whose BMI decreased, our results can be seen as consistent with prior research suggesting that a lower BMI predisposes to hypoglycemia. Analysis of data from 11,140 patients with T2D enrolled in the ADVANCE study revealed a reduced risk of severe hypoglycemia with increasing BMI [21]. Similar results were obtained in a post hoc analysis of the ACCORD trial including 10,209 T2D patients, where a BMI exceeding $30 \mathrm{~kg} / \mathrm{m}^{2}$ was found to be associated with a significantly lower risk of hypoglycemia requiring medical attention than a BMI below $25 \mathrm{~kg} / \mathrm{m}^{2}$ [22]. Our results add further to the body of evidence suggesting that a higher BMI may be somewhat protective against hypoglycemia.

The total number of hypoglycemic events was analyzed based on patients' subjective assessment of any symptomatic hypoglycemic episodes. Hypoglycemic episodes after three and six months were reported by $8.5 \%$ and $5.2 \%$ of patients, respectively, and were less common compared to baseline. The decrease in hypoglycemic episode incidence after between three and six months of therapy could be due to a dose optimization period. These hypoglycemic events were reported more frequently among the basal bolus subpopulation, which may explain why a significantly smaller number of patients in this group reached the composite therapeutic goal (Table 3). Even those patients with the most advanced form of diabetes benefited from switching to the insulin glargine regimen-the decrease in the number of hypoglycemic events and the achievement of the therapeutic target throughout the follow-up period was similar in patients with advanced diabetes compared to those in other subpopulations. Overall, our results suggest that basal insulin therapy was associated with a lower risk of hypoglycemia, a low risk of nocturnal hypoglycemia, and no serious events of hypoglycemia observed in patients switched to insulin glargine regimens.

Apart from its clinical advantages concerning glycemic control, the insulin glargine regimen was also well perceived by the patients. Indeed, basal insulin regimens allow a better quality of life due to not only the benefits of obtaining tight glycemic control but also those associated with fewer injections and more comfortable bedtime administration.

We presented evidence from a real-world clinical setting that were largely consistent across different analysis subgroups within this study. Nevertheless, one should be aware of the limitations associated with our research, such as the biases related to the unblinded noninterventional nature of this observational study and the lack of randomization. The results obtained for analysis subpopulations should be interpreted in light of baseline patient characteristics, and no causal relationship between the treatment and outcomes could be established incontrovertibly. Furthermore, our analysis is limited as data on hypoglycemia were collected both retrospectively (for pre-mixed insulin therapy) and prospectively (for basal insulin therapy), which makes it difficult to compare 
them. Finally, the number of patients receiving non-metformin OADs was small, prohibiting a more detailed analysis of the effects of concomitant therapy on the efficacy and safety of insulin glargine-based regimens.

\section{CONCLUSIONS}

The results of this observational study show that insulin glargine has a good safety profile and is effective at improving glycemic control in a large, diverse population with long-standing T2D and who were previously uncontrolled with pre-mixed insulin therapy. We observed that patients treated with different insulin glargine regimens (with either OADs only, or with additional prandial insulin) achieved improved glycemic control, a low incidence of hypoglycemia, and a decrease in body weight. Although descriptive to a large extent, the results of our study may aid the therapeutic decision process for other physicians and for patients who could benefit from the clinical advantages of insulin glargine shown here.

\section{ACKNOWLEDGEMENTS}

The authors would like to thank Tomasz Stepkowski, Katarzyna Domek-Łopacińska, and Agnieszka Linkiewicz-Zegan from Proper Medical Writing Sp. z o.o., Warsaw, Poland, for providing writing and formatting support as well as preparing the figures, and Julia Bates, Ph.D., from Proper Medical Writing Sp. z o.o., Warsaw, Poland, for undertaking language editing and proofreading. This support was funded by Sanofi-Aventis Croatia d.o.o., Zagreb, Croatia.

Funding. Sanofi-Aventis Croatia d.o.o., Zagreb, Croatia, provided financial support for the conduct of the study, editorial assistance, and article processing charges. All authors had full access to all of the data in this study and take complete responsibility for the integrity of the data and accuracy of the data analysis.

Authorship. All named authors meet the International Committee of Medical Journal
Editors (ICMJE) criteria for authorship for this article, take responsibility for the integrity of the work as a whole, and have given their approval for this version to be published.

Disclosures. Goran Petrovski declares associations (lecturer, clinical trial investigator) with the following companies: Eli Lilly, Novo Nordisk, Sanofi-Aventis, Medtronic, and Alkaloid. Dashamir Gjergji declares associations (lecturer, clinical trials investigator, advisor) with the following companies: Novartis, Novo Nordisk, Sanofi. Aleksandra Grbic declares associations (lecturer, clinical trial investigator) with the following companies: Eli Lilly, Novo Nordisk, Takeda, and Novartis. Blazenko Vukovic declares associations (lecturer, clinical trial investigator) with Sanofi, Novo Nordisk, Eli Lilly, Takeda, Novartis. Mitja Krajnc declares associations (lecturer, clinical trial investigator, advisory board member) with the following companies: Sanofi-Aventis, Eli Lilly, AstraZeneca, Boehringer Ingelheim, Krka, Mylan. Natasa Grulovic is an employee of Sanofi.

Compliance with Ethics Guidelines. The study has been approved by the appropriate ethics committees: Ethics Committee, Ministry of Health, Republic of Macedonia; Republic of Slovenia National Medical Ethics Committee; National Committee of Medical Ethics, Albania; and the ethics committees of the institutions in which the study was conducted (e.g., the ethics committees of Clinical Hospital Mostar, Clinical Hospital Zenica, General Hospital Trebinje, Health Center Tuzla) in Bosnia and Herzegovina. All procedures performed in studies involving human participants were in accordance with the ethical standards of the institutional and/or national research committee and with the 1964 Helsinki Declaration and its later amendments or comparable ethical standards. Informed consent was obtained from all individual participants included in the study.

Data Availability. The datasets generated during and/or analyzed during the current study are available from the corresponding author on reasonable request. 
Open Access. This article is distributed under the terms of the Creative Commons Attribution-NonCommercial 4.0 International License (http://creativecommons.org/licenses/ by-nc/4.0/), which permits any noncommercial use, distribution, and reproduction in any medium, provided you give appropriate credit to the original author(s) and the source, provide a link to the Creative Commons license, and indicate if changes were made.

\section{REFERENCES}

1. Chen L, Magliano DJ, Zimmet PZ. The worldwide epidemiology of type 2 diabetes mellitus-present and future perspectives. Nat Rev Endocrinol. 2011;8:228-36.

2. Chan JC, Gagliardino JJ, Baik SH, Chantelot JM, Ferreira SR, Hancu N, et al. Multifaceted determinants for achieving glycemic control: the International Diabetes Management Practice Study (IDMPS). Diabetes Care. 2009;32:227-33.

3. Wake N, Hisashige A, Katayama T, Kishikawa H, Ohkubo Y, Sakai M, et al. Cost-effectiveness of intensive insulin therapy for type 2 diabetes: a 10-year follow-up of the Kumamoto study. Diabetes Res Clin Pract. 2000;48:201-10.

4. Canadian Diabetes Association Clinical Practice Guidelines Expert Committee, Harper W, Clement M, Goldenberg R, Hanna A, Main A, et al. Pharmacologic management of type 2 diabetes. Can J Diabetes. 2013;37(Suppl 1):S61-8.

5. Nathan DM, Buse JB, Davidson MB, Ferrannini E, Holman RR, Sherwin R, et al. Medical management of hyperglycemia in type 2 diabetes: a consensus algorithm for the initiation and adjustment of therapy: a consensus statement of the American Diabetes Association and the European Association for the Study of Diabetes. Diabetes Care. 2009;32:193-203.

6. Vaag A, Lund SS. Insulin initiation in patients with type 2 diabetes mellitus: treatment guidelines, clinical evidence and patterns of use of basal vs premixed insulin analogues. Eur J Endocrinol. 2012;166:159-70.

7. Donner T. Insulin-pharmacology, therapeutic regimens and principles of intensive insulin therapy. In: De Groot LJ, Chrousos G, Dungan K, Feingold KR, Grossman A, Hershman JM, Koch C, Korbonits M, McLachlan R, New M, et al., editors.
Endotext. South Dartmouth, MA: MDText.com, Inc.; 2000.

8. Eliaschewitz FG, Calvo C, Valbuena H, Ruiz M, Aschner P, Villena J, et al. Therapy in type 2 diabetes: insulin glargine vs. NPH insulin both in combination with glimepiride. Arch Med Res. 2006;37:495-501.

9. Goykhman S, Drincic A, Desmangles JC, Rendell M. Insulin glargine: a review 8 years after its introduction. Expert Opin Pharmacother. 2009;10:705-18.

10. Riddle MC, Rosenstock J, Gerich J, Insulin Glargine 4002 Study Investigators. The treat-to-target trial: randomized addition of glargine or human $\mathrm{NPH}$ insulin to oral therapy of type 2 diabetic patients. Diabetes Care. 2003;26:3080-6.

11. Rosenstock J, Schwartz SL, Clark CM Jr, Park GD, Donley DW, Edwards MB. Basal insulin therapy in type 2 diabetes: 28-week comparison of insulin glargine (HOE 901) and NPH insulin. Diabetes Care. 2001;24:631-6.

12. Heinemann L, Linkeschova R, Rave K, Hompesch B, Sedlak M, Heise T. Time-action profile of the longacting insulin analog insulin glargine (HOE901) in comparison with those of NPH insulin and placebo. Diabetes Care. 2000;23:644-9.

13. Hilgenfeld R, Seipke G, Berchtold H, Owens DR. The evolution of insulin glargine and its continuing contribution to diabetes care. Drugs. 2014;74:911-27.

14. Cigrovski Berkovic M, Petrovski G, Grulovic N. Effectiveness of insulin glargine in type 2 diabetes mellitus patients failing glycaemic control with premixed insulin: Adriatic countries data metaanalysis. Acta Diabetol. 2016;53:709-15.

15. Riebenfeld D, Spirk D, Mathis A, Villiger L, Gerber PA, Gasser UE, et al. Treatment intensification with insulin glargine in patients with inadequately controlled type 2 diabetes improves glycaemic control with a high treatment satisfaction and no weight gain. Swiss Med Wkly. 2015;145:w14114.

16. Zhang Y, Xie YJ, Meng DD, Zhang HH, Chen H, Liu E. Clinical study of treatment switching from premixed insulin to basal insulin combined with oral hypoglycemic drugs in patients with type 2 diabetes. Diabetol Metab Syndr. 2014;6:37.

17. International Diabetes Federation. The IDF consensus worldwide definition of the metabolic syndrome. Brussels: IDF Communications; 2006.

18. Bellido V, Suarez L, Rodriguez MG, Sanchez C, Dieguez M, Riestra M, et al. Comparison of basal- 
bolus and premixed insulin regimens in hospitalized patients With type 2 diabetes. Diabetes Care. 2015;38:2211-6.

19. Davies M, Sinnassamy P, Storms F, Gomis R. Insulin glargine-based therapy improves glycemic control in patients with type 2 diabetes sub-optimally controlled on premixed insulin therapies. Diab Res Clin Pract. 2008;79:368-75.

20. American Diabetes Association. 7. Obesity management for the treatment of type 2 diabetes. Diabetes Care. 2017;40(Suppl 1):S57-63.
21. Zoungas S, Patel A, Chalmers J, de Galan BE, Li Q, Billot L, et al. Severe hypoglycemia and risks of vascular events and death. $\mathrm{N}$ Engl $\mathrm{J}$ Med. 2010;363:1410-8.

22. Miller ME, Bonds DE, Gerstein HC, Seaquist ER, Bergenstal RM, Calles-Escandon J, et al. The effects of baseline characteristics, glycaemia treatment approach, and glycated haemoglobin concentration on the risk of severe hypoglycaemia: post hoc epidemiological analysis of the ACCORD study. BMJ. 2010;340:b5444. 